\title{
Immunosuppression, sialic acid, and sialyltransferase of bovine serum as a function of progesterone concentration
}

\author{
A. P. Sherblom, R. M. Smagula, C. E. Moody* and G. W. Anderson $\dagger$ \\ Departments of Biochemistry, *Microbiology and $\uparrow$ Animal and Veterinary Science, \\ University of Maine, Orono, ME 04469, U.S.A.
}

\begin{abstract}
Summary. Serum samples from progesterone-oestrogen-treated ovariectomized Holstein cows $(N=4)$ were compared with samples from control ovariectomized Holstein cows $(\mathrm{N}=4)$ to determine the effects of physiological levels $(0-6 \mathrm{ng} / \mathrm{ml})$ of circulating progesterone. The average progesterone level in treated animals rose from $1 \mathrm{ng} / \mathrm{ml}$ (Day 0 ) to plateau at $5 \mathrm{ng} / \mathrm{ml}$ (Days 12 to 36 ). Sera from progesterone-oestrogen-treated cows during Days 4 to 10 significantly suppressed stimulation of lymphocytes by phytohaemagglutinin as compared with sera from control cows $(P=0.02)$, whereas no differences were detected in serum samples from Days 12 to 36 . Serum samples from progesterone-oestrogen-treated or control cows did not affect the stimulation of lymphocytes by pokeweed mitogen. Sialyltransferase activity $(P=0.0002)$ and sialic acid content $(P=0.006)$ were both significantly elevated in serum from progesteroneoestrogen-treated animals compared with controls during Days 8 to 16 , whereas no significant differences were observed at later times. The results suggest that suppression of phytohaemagglutinin-induced stimulation, sialic acid content, and sialyltransferase activity are sensitive not to the circulating level of progesterone but rather to increases in progesterone concentration, with maximal effects observed at Days 8, 12 and 12, respectively, after the start of progesterone treatment. The work provides a preliminary basis for further studies on the mechanism of immunosuppression by steroids and during pregnancy.
\end{abstract}

\section{Introduction}

The mechanism by which the fetus escapes immunological rejection by the maternal host remains an unsolved mystery. Amongst the several processes which may be involved, suppression of the maternal immune system at the local or systemic level is certain to play a role. Localized uterine immunosuppression in pregnant and progesterone-treated animals has been observed through skin-graft studies (Watnick \& Russo, 1968; Beer, Billingham \& Scott, 1975) and through demonstration of an immunosuppressive uterine protein (Roberts, 1977; Etzel, Murray, Grifo \& Kinder, 1978). Systemic maternal immunosuppression is supported by studies demonstrating that maternal human (Kasakura, 1971), bovine (Manak, 1981) and murine (Hellstrom, Hellstrom \& Brawn, 1969) plasma suppresses the reactivity to mitogens (Purtilo, Hallgren \& Yunis, 1972; Leiken, 1972; Hsu, 1974).

The role of progesterone in maternal immunosuppression is currently in debate. Progesterone inhibits allograft rejection in vivo (Hulka, Mohr \& Lieberman, 1965) and inhibits in-vitro stimulation of human (Clemens, Siiteri \& Stites, 1979; Mori et al., 1975) but not bovine (Murray \& Chenault, 1982) lymphocytes. Although concentrations of progesterone are higher in the region of the trophoblast (Clemens et al., 1979) and in lymphatic fluid (Staples, Fleet \& Heap, 1982) than in peripheral blood $(1-20 \mathrm{ng} / \mathrm{ml})$, it is not clear whether the level of progesterone at any of these sites is sufficient to produce the immunosuppression observed in vitro $\left(10^{3}-10^{4} \mathrm{ng} / \mathrm{ml}\right)$. One possibility is 
that progesterone influences immune function indirectly rather than directly, by inducing the synthesis of immunomodulatory proteins or glycoproteins (Murray \& Chenault, 1982). Pregnancyspecific glycoproteins have been described (Koch, Morton \& Ellendorff, 1983; Sarcione, Delluomo \& Zloty, 1983) and glycoprotein synthesis is influenced by oestrogen and progesterone (Nelson, Jato-Rodriguez, Labrie \& Mookerjea, 1977; Singh \& Lucas, 1981).

The present study was undertaken to (a) establish whether circulating levels of progesterone similar to those found during pregnancy are sufficient to result in systemic immunosuppression as determined by in-vitro analysis of serum, and (b) test the hypothesis that immunosuppression by serum is related to changes in glycoprotein synthesis. To our knowledge, there are no previous studies on serum sialic acid or sialyltransferase as related to pregnancy or progesterone concentration.

\section{Materials and Methods}

Materials. $\left[{ }^{3} \mathrm{H}\right]$ Thymidine (sp. act. $2 \mathrm{Ci} / \mathrm{mmol}$ ) and $\left[{ }^{14} \mathrm{C}\right] \mathrm{CMP}-$ sialic acid (sp. act. $1.6 \mathrm{mCi} / \mathrm{mmol}$ ) were purchased from New England Nuclear, Boston, MA, U.S.A. Histopaque, fetuin, and pokeweed mitogen were from Sigma, St Louis, MO, U.S.A. RPMI 1640 medium, fetal bovine serum, glutamine and antibiotics were obtained from Gibco, Grand Island, NY, U.S.A. Phytohaemagglutinin was a product of Burroughs-Wellcome, Research Triangle Park, NC, U.S.A., and progesterone and oestrogen were purchased from Steraloids, Wilton, NH, U.S.A. Liquiscint was from National Diagnostics, Summerville, NJ, U.S.A. Asialofetuin was prepared by hydrolysis of fetuin $\left(0.05 \mathrm{M}-\mathrm{H}_{2} \mathrm{SO}_{4}, 1 \mathrm{~h}, 80^{\circ} \mathrm{C}\right)$, neutralization, dialysis against distilled water, and freeze drying.

Serum samples. Eight mature non-lactating Holstein cows were ovariectomized on Day 4 of the oestrous cycle by high lumbar laparotomy, and this was taken as Day 0 of the experiment. Four cows received daily subcutaneous injections of progesterone $(0.5 \mathrm{mg} / \mathrm{kg})$ and oestradiol-17 $(0.125$ $\mu \mathrm{g} / \mathrm{kg}$ ) in a vehicle of $90 \%$ corn oil $/ 10 \%$ ethanol, whereas control animals were injected with vehicle. Blood samples were collected by jugular venepuncture into sterile untreated vacutainer tubes at Day 0,1 and 2 and every other day until 36 days after ovariectomy. Samples were allowed to clot overnight at $4^{\circ} \mathrm{C}$, and after centrifugation $(400 \mathrm{~g}, 30 \mathrm{~min})$ the serum was transferred to sterile vials and stored at $-80^{\circ} \mathrm{C}$. Samples were analysed for protein by the method of Lowry, Rosebrough, Farr \& Randall (1951) and for sialic acid content by the method of Warren (1959) following hydrolysis with $0.05 \mathrm{M}-\mathrm{H}_{2} \mathrm{SO}_{4}$ at $80^{\circ} \mathrm{C}$ for $1 \mathrm{~h}$ and neutralization. Progesterone was determined by radioimmunoassay according to Butcher, Collins \& Fugo (1974) as modified by Sheffel, Pratt, Ferrell \& Inskeep (1982).

Determination of immunosuppressive activity. Peripheral blood lymphocytes used in the immunosuppression assay were collected from the same control animal (No. 767) throughout the study. Blood samples were taken between 2 and 8 months from Day 0 into heparinized vacutainer tubes. Lymphocytes were prepared by density gradient centrifugation over Histopaque according to Sigma Technical Bulletin 1077. Briefly, blood was diluted with $1.4 \mathrm{ml}$ phosphate-buffered saline per $\mathrm{ml}$ blood; the diluted blood $(30 \mathrm{ml})$ was layered onto Histopaque $1077(15 \mathrm{ml})$ and centrifuged at $400 \mathrm{~g}$ for $40 \mathrm{~min}$. The interphase was collected and washed 3 times with phosphate-buffered saline. From $60 \mathrm{ml}$ blood, typically 3-6 $\times 10^{7}$ lymphocytes were recovered with a viability $>98^{\circ} \%$. Lymphocytes (2-4 $\times 10^{5}$ cells) were cultured in 96-well, round-bottom microtitre plates (Linbro) in a final volume of $200 \mu \mathrm{l} /$ well. Culture medium consisted of RPMI 1640 supplemented with $10 \%$ fetal bovine serum, $2 \mathrm{~mm}$-glutamine, 100 units penicillin $/ \mathrm{ml}, 100 \mu \mathrm{g}$ streptomycin $/ \mathrm{ml}$, and $25 \mathrm{~mm}$ Hepes. Cultures were incubated for $48 \mathrm{~h}$ at $37^{\circ} \mathrm{C}$ in a $5 \% \mathrm{CO}_{2} / 95 \%$ air humidified atmosphere. $\left[{ }^{3} \mathrm{H}\right]$ Thymidine $(1 \mu \mathrm{Ci} /$ well $)$ was added for the last $8 \mathrm{~h}$ of culture. Cells were collected on glass-fibre filters and washed with distilled water using an M-12 cell harvester (Brandel), and $3 \mathrm{ml}$ of Liquiscint were added to each filter in a $7 \mathrm{ml}$ scintillation vial for counting. All cultures were 
performed in triplicate. Mitogen-stimulated cultures contained a previously determined optimal concentration of phytohaemagglutinin $(1.0 \mu \mathrm{g} / \mathrm{ml})$ or pokeweed mitogen $(10 \mu \mathrm{g} / \mathrm{ml})$ and typical assays contained $5 \mu \mathrm{l}$ of test or control serum in $200 \mu 1$ total volume. To calculate immunosuppression, the increase in c.p.m. due to addition of mitogen in the presence of test serum was divided by the increase observed in the absence of serum; this value was subtracted from 1 and the result expressed as $\%$.

Sialyltransferase assay. The assay mixture contained the following concentrations of components in a total volume of $100 \mu \mathrm{l}: 50 \mathrm{~mm}-\mathrm{Hepes}, \mathrm{pH} 6 \cdot 5,10 \mathrm{mM}-\mathrm{MnCl}_{2}, 0 \cdot 1 \%$ Triton X-100, $\left[{ }^{14} \mathrm{C}\right] \mathrm{CMP}-$ sialic acid $(0.4 \mathrm{mM}, 0.6 \mu \mathrm{Ci} / \mathrm{ml})$, asialofetuin $(2.5 \mathrm{mg} / \mathrm{ml})$, and serum $(25 \% \mathrm{v} / \mathrm{v})$. All assays were performed in duplicate with and without the acceptor asialofetuin, and all values reported have been corrected for endogenous activity. Assay mixtures were incubated for $1 \mathrm{~h}$ at $37^{\circ} \mathrm{C}$, and quenched with cold $0.5 \mathrm{M}-\mathrm{HCl}, 1 \%$ phosphotungstic acid. The pellet was washed twice with cold $10 \%$ trichloroacetic acid and once with ethanol : ether $(2: 1 \mathrm{v} / \mathrm{v})$. Soluene $350(0.5 \mathrm{ml})$ and Instagel $(5 \mathrm{ml})$ were added before scintillation counting.

\section{Results}

\section{Progesterone concentration}

Progesterone concentrations in the sera of treated and control cows are shown in Text-fig. 1 as a function of time. For the control animals, the progesterone concentration averaged $0.6-0.8 \mathrm{ng} / \mathrm{ml}$ from Day 4 until Day 36. For the progesterone-treated cows, the progesterone values increased from Day 0 to Day 12, stabilizing at a value of around $5 \mathrm{ng} / \mathrm{ml}$ from Day 20 to Day 36. This concentration of circulating progesterone is similar to the physiological levels observed during ovulation and pregnancy (Bazer \& First, 1983).

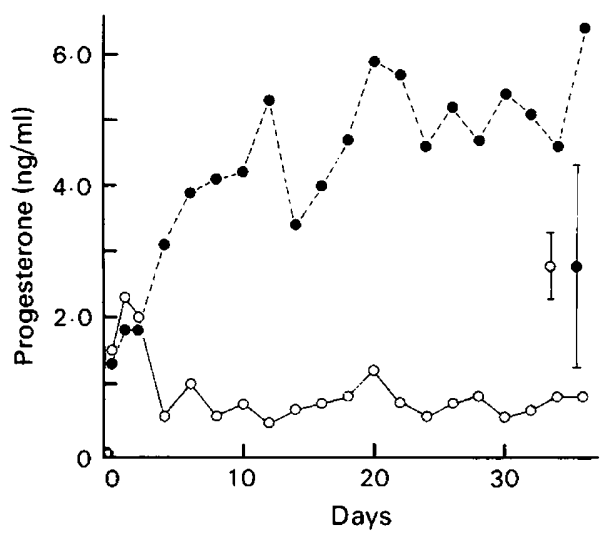

Text-fig. 1. Progesterone concentration in bovine serum as a function of time. Samples from progesterone-treated $(O)$ and control $(O)$ cows were assayed for progesterone. Error bars at the right represent an average of the standard errors of the means for each time point $(N=4)$.

\section{Immunosuppressive activity}

In preliminary experiments, the duration of incubation (1-6 days) and the concentration of each mitogen $(0 \cdot 1$ to $100 \mu \mathrm{g} / \mathrm{ml})$ were varied to determine optimal conditions for lymphocyte proliferation. For the current studies a culture time of 2 days was used and concentrations of $1.0 \mu \mathrm{g}$ phytohaemagglutinin/ml and $10 \mu \mathrm{g}$ pokeweed mitogen $/ \mathrm{ml}$ gave optimal incorporation of $\left[{ }^{3} \mathrm{H}\right]$ thymidine. Various amounts of serum were also tested, and $5 \mu \mathrm{l}$ serum $/ 200 \mu \mathrm{l}$ was chosen since higher values did not result in increased immunosuppression. 
Control cultures containing only lymphocytes typically incorporated 200-300 c.p.m. from $\left[{ }^{3} \mathrm{H}\right]$ thymidine, whereas cultures stimulated with either mitogen incorporated $15000-30000$ c.p.m. Addition of serum to control cultures did not change the c.p.m. incorporated, although occasionally values as high as 500-600 c.p.m. were observed. The values of immunosuppression reported are, therefore, due primarily to the difference in c.p.m. incorporated in mitogen-stimulated cultures in the presence and absence of serum.

There was considerable variability in the immunosuppression assay, even though the lymphocytes were obtained from the same animal. Serum samples assayed at different times gave values which could differ by $\pm 15 \%$ in immunosuppression. For this reason, all the serum samples from the same animal were assayed at the same time.

The plot of immunosuppression as a function of time is shown in Text-fig. 2. Addition of serum to phytohaemagglutinin-stimulated cultures typically resulted in a slight stimulation with control sera averaging $15 \%$ stimulation (or $-15 \%$ immunosuppression). Sera from progesterone-treated cows at Days 4 to 10 showed immunosuppressive activity. However, with the low number of observations $(\mathrm{N}=4)$ and the variability in the assay, differences between control and treated samples at any particular time were not significant. A significant difference $(P=0.02)$ between

Table 1. Average values of immunosuppression in serum of control and progesterone-treated cows

\begin{tabular}{ccccc}
\hline Mitogen & & Days 4-10 & Days 12-18 & Days 20-28 \\
\hline Phytohaemagglutinin & Control & $-7 \pm 9$ & $-17 \pm 10$ & $-9 \pm 6$ \\
& Treated & $23 \pm 8^{*}$ & $-35 \pm 7$ & $-8 \pm 6$ \\
Pokeweed mitogen & Control & $17 \pm 8$ & $16 \pm 5$ & $14 \pm 6$ \\
& Treated & $10 \pm 6$ & $3 \pm 8$ & $0 \pm 8$ \\
\hline
\end{tabular}

Each value represents the mean of 4 observations averaged over 4 time points.

* Significantly different from control $(P=0.02)$ by paired-comparison $t$ test.

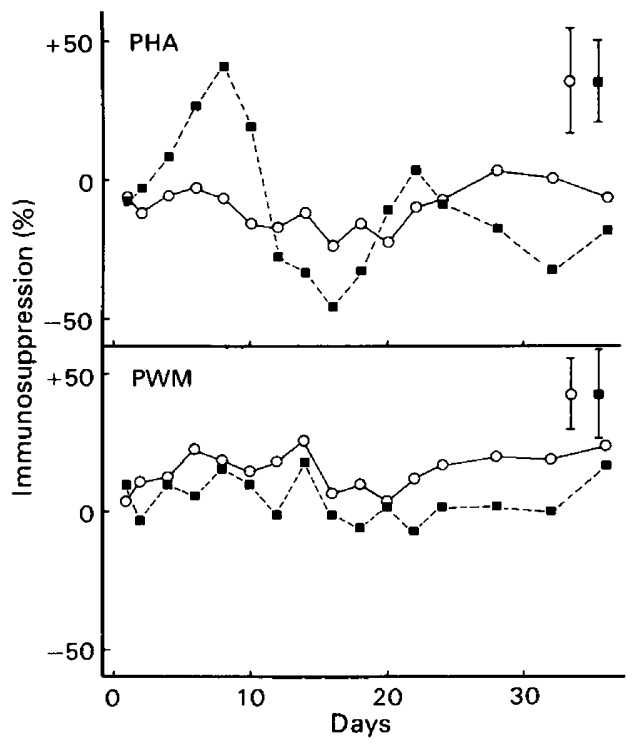

Text-fig. 2. Immunosuppressive activity of bovine serum as a function of time. Serum samples from progesterone-treated $(\square)$ and control $(O)$ cows were tested for the ability to inhibit proliferation of peripheral lymphocytes stimulated by phytohaemagglutinin (PHA) or pokeweed mitogen (PWM). Error bars at the right represent an average of the standard errors of the means for each time point $(N=4)$. 
control and treated samples was seen if values from Days 4 to 10 were averaged, thereby increasing the number of observations from 4 to 16 (Table 1). Differences during other blocks of time were not significant. Despite the variation between animals, samples from all 4 progesterone-treated cows showed a pronounced increase in immune suppression with phytohaemagglutinin during Days 610. In contrast, serum from the control and treated cows minimally suppressed stimulation by pokeweed mitogen $5-15 \%$, and there was no difference in suppression by control or treated sera.

\section{Sialic acid content}

The average $(\mathrm{N}=4)$ concentration of sialic acid in serum ranged from 1.2 to $1.8 \mu \mathrm{mol} / \mathrm{ml}$, whereas individual samples ranged from 0.4 to $2.3 \mu \mathrm{mol} / \mathrm{ml}$. These concentrations are similar to those reported for human serum, for which the upper limit of normal concentration was determined to be $2.0 \mu \mathrm{mol} / \mathrm{ml}$ (Silver, Karim, Archibald \& Salinas, 1979; Silver, Murray, Worth, Salinas \& Spinelli, 1983). Sialic acid values in samples from the control and treated cows increased from Days 1 to 6, and decreased from Days 26 to 36 (Text-fig. 3). Progesterone-oestrogen-treated cows showed a prominent peak in sialic acid content at Day 12. Since each time point contained only 4 observations, data from 5 time points were averaged before statistical analysis by $t$ test (Table 2). The results show that, in blocks of time from Day 0 to Day 6 and Day 18 to Day 36, there was no significant difference in serum sialic acid content of control and treated cows. The peak that occurred in progesterone-treated cows between Days 8 and 16 was significantly greater than control values for the same block of time $(P=0.006)$. The timing of the peak coincided with the peak in serum progesterone concentration, which occurred at Day 12.

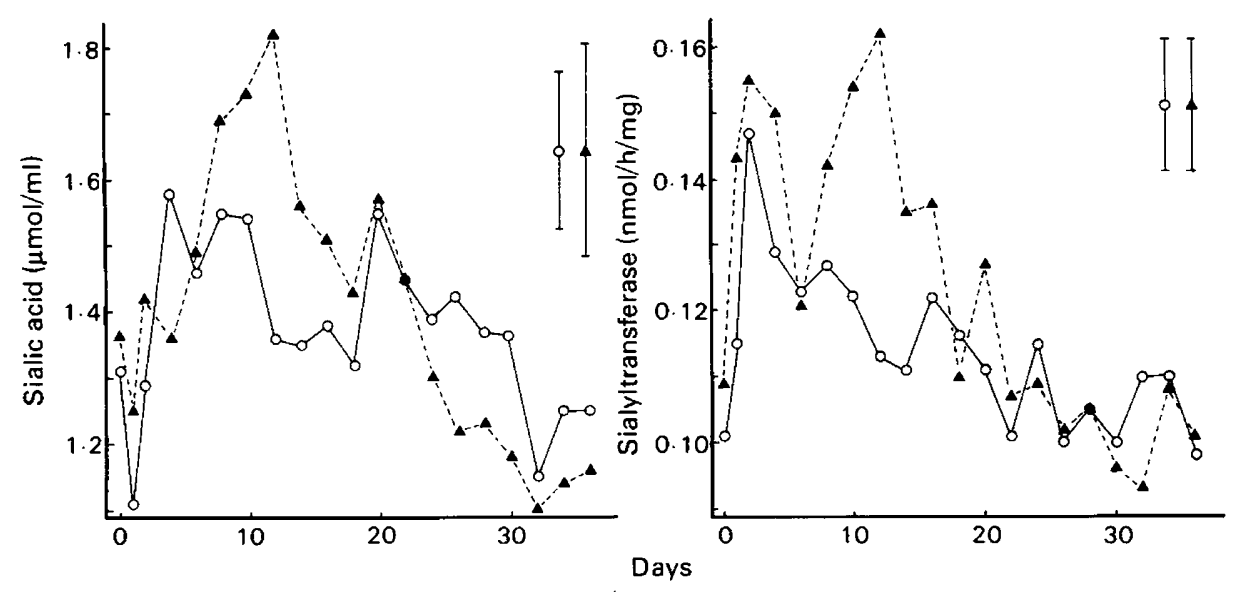

Text-fig. 3. Sialic acid concentration and sialyltransferase activity in bovine serum as a function of time. Serum samples from progesterone-treated $(\boldsymbol{A})$ and control $(O)$ cows were assayed as described in 'Materials and Methods'. Error bars at the right represent an average of the standard errors of the means for each time point $(\mathrm{N}=4)$.

\section{Sialyltransferase activity}

Preliminary studies of sialyltransferase activity in bovine serum were performed to establish optimum conditions for the assay. In particular, incorporation was found to be linear for $1 \mathrm{~h}$ and to be linear with sample concentration up to $30 \mu \mathrm{l}$ serum $/ 100 \mu \mathrm{l}$ total volume. The concentration of the acceptor asialofetuin in the assay was chosen to be $2.5 \mathrm{mg} / \mathrm{ml}$, since this level gave optimal activity and inhibition of incorporation occurred at concentrations above $4 \mathrm{mg} / \mathrm{ml}$. Average activities ranged from $0 \cdot 10$ to $0.16 \mathrm{nmol} / \mathrm{h} / \mathrm{mg}$ with individual samples from 0.06 to $0.20 \mathrm{nmol} / \mathrm{h} / \mathrm{mg}$. These 
Table 2. Average values of sialic acid content and sialyltransferase activity in serum of control and progesterone-treated cows

\begin{tabular}{lcccc}
\hline & Days 0-6 & Days 8-16 & Days 18-26 & Days 28-36 \\
\hline Control & $1.34 \pm 0.06$ & $1.43 \pm 0 \cdot 04$ & Sialic acid $(\mu \mathrm{mol} / \mathrm{ml})$ \\
Treated & $1.38 \pm 0.04$ & $1.66 \pm 0.07^{*}$ & $1.39 \pm 0.06$ & $1.28 \pm 0.07$ \\
& & Sialyltransferase & $(\mathrm{nmol} / \mathrm{h} / \mathrm{mg})$ \\
Control & $0.123 \pm 0.006$ & $0.119 \pm 0.004$ & $0 \cdot 109 \pm 0.005$ & $1 \cdot 16 \pm 0 \cdot 10$ \\
Treated & $0 \cdot 136 \pm 0.007$ & $0.146 \pm 0.005^{*}$ & $0 \cdot 111 \pm 0.004$ & $0.105 \pm 0.004$ \\
\end{tabular}

Each value represents the mean of 4 observations averaged over 5 time points.

* Significantly different from control $(P=0.01)$ by paired-comparison $t$ test.

values are roughly equivalent to values of sialyltransferase reported in serum of humans $(0 \cdot 36$ $\mathrm{nmol} / \mathrm{h} / \mathrm{mg}$; Silver et al., 1979) and rats $(0 \cdot 1-0 \cdot 3 \mathrm{nmol} / \mathrm{h} / \mathrm{mg}$; Dairaku, Miyagi, Wakui \& Tsuiki, 1983).

The profiles of sialyltransferase activity as a function of time (Text-fig. 3) have features that are common with the sialic acid profiles. The most striking aspect is the peak of activity which occurred in progesterone-treated cows at Day 12. The difference between control and treated cows was significant $(P=0.0002)$ only for values averaged from Days 8 to 16 (Table 2 ).

In addition to the major peak of activity occurring at Day 12 in treated cows, there was an early rise in sialyltransferase activity, which peaked at Day 2 in control and treated animals. This early peak may be a result of the stress associated with ovariectomy, since elevated values of sialyltransferase may accompany inflammation (Kaplan, Woloski, Hellman \& Jamieson, 1983) or tissue regeneration (Van Dijk, Lasthuis, Trippelvite \& Muilerman, 1983). However, the peak in sialyltransferase activity which occurs at Day 12 in treated animals cannot be attributed to the ovariectomy. The difference between values from treated and control animals, which had also been ovariectomized, was significant. Furthermore, preliminary studies of the specificity of the enzyme on Day 12 sera were performed as described by Sherblom \& Bourassa (1983) with lactose as the acceptor. The results showed that the enzyme was predominantly a galactose- $R(\alpha 2 \rightarrow 3)$ sialyltransferase rather than the galactose- $R(\alpha 2 \rightarrow 6)$ sialyltransferase associated with inflammation (Kaplan et al., 1983) (data not shown).

\section{Discussion}

Previous studies have shown that high levels of progesterone $\left(10^{3}-10^{4} \mathrm{ng} / \mathrm{ml}\right)$ result in in-vitro immunosuppression of human (Mori et al., 1975; Clemens et al., 1979) but not bovine (Murray \& Chenault, 1982) lymphocytes. In the current work immunosuppression was observed in serum samples in which the circulating progesterone concentration was in the normal physiological range (4-6 ng/ml). The suppression of lymphocyte proliferation appeared to be a function of rising progesterone concentration, because as the progesterone concentration reached a plateau immunosuppressive activity returned to control values (Text-fig. 2). The results cannot be due solely to the presence of progesterone in the serum samples, because the effective concentration in the assay is too low $(0 \cdot 1-0 \cdot 2 \mathrm{ng} / \mathrm{ml})$ to result in immunosuppression, and because samples with the highest levels of progesterone (Days 12 to 36 ) did not have immunosuppressive activity. Progesterone treatment is known to induce synthesis of immunosuppressive uterine proteins (Roberts, 1977; Etzel et al., 1978), and the current study suggests that this is a systemic rather than a localized phenomenon.

The immunosuppression observed in progesterone-treated animals appeared to be directed towards $T$ rather than $B$ lymphocytes, since significant differences were observed with 
phytohaemagglutinin but not pokeweed mitogen. This is of interest since progesterone itself is thought to suppress specifically proliferation of $T$ lymphocytes in vitro (Stites, Bugbee \& Siiteri, 1983; Stites \& Siiteri, 1983).

Sialic acid content and sialyltransferase activity were also sensitive to rising levels of progesterone. The increasing sialyltransferase activity and sialic acid content paralleled closely the increasing level of progesterone (compare Text-fig. 3 with Text-fig. 1). After the peak in progesterone concentration at Day 12 , sialyltransferase activity and sialic acid content of treated sera declined to reach control values at about Day 20. Previous work indicates that treatment of rat endometrium with progesterone results in an elevation of sialyltransferase activity at low concentrations but an inhibition at higher levels (Nelson, Jato-Rodriguez \& Mookerjea, 1975).

Any connection between sialyltransferase activity, sialic acid, and immunosuppression of phytohaemagglutinin-stimulated lymphocytes in progesterone-treated animals is, at this point, speculative. All three factors are sensitive to rising levels of progesterone in the range of $0-6 \mathrm{ng} / \mathrm{ml}$. Sialyltransferase activity and sialic acid content reach peak values when the progesterone concentration is maximal (Day 12), whereas immunosuppressive activity with phytohaemagglutinin peaks earlier at Day 8.

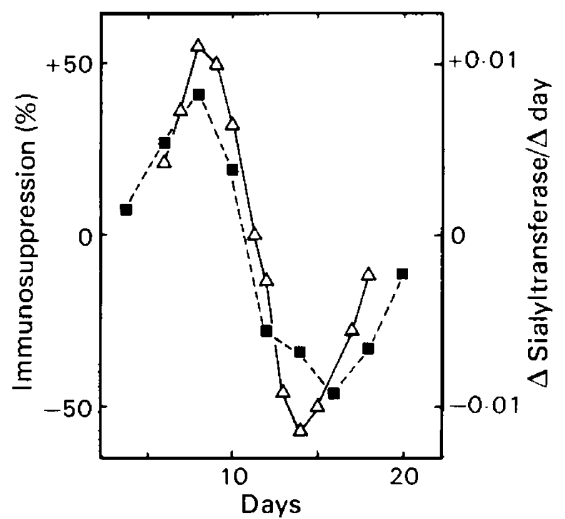

Text-fig. 4. Comparison of immunosuppressive activity with phytohaemagglutinin with the derivative of sialyltransferase activity in sera of progesterone-treated cows. Immunosuppressive activity ( $(\mathbb{0})$ with phytohaemagglutinin is as shown in Text-fig. 2 . A smooth curve of sialyltransferase activity in sera of progesterone-treated cows was generated using the values shown in Text-fig. 3, and the slope of the tangent to the curve was determined for each day from Days 6 to 18 to generate $\Delta$ sialyltransferase $/ \Delta$ day $(\triangle)$, which has the units $(\mathrm{nmol} / \mathrm{h} / \mathrm{mg}) /$ day.

Two comments can be made concerning the relationship between immunosuppressive activity with phytohaemagglutinin and sialyltransferase activity. First, although the two are not directly correlated, there appears to be a close correlation between immunosuppressive activity and the derivative or rate of change of sialyltransferase activity with time (Text-fig. 4). Second, it is possible that progesterone stimulates synthesis of glycoproteins which are immunosuppressive, but that sialyltransferase activity is a marker for a late phase in the process. In support of this hypothesis is the specificity of the lectin phytohaemagglutinin for galactose residues, which suggests that glycoproteins containing galactose as the terminal sugar will be most effective as immunosuppressants. Completion of the carbohydrate chain by addition of sialic acid to the galactose would be expected to reduce the immunosuppressive activity with phytohaemagglutinin.

Furthermore, studies of rat endometrium have shown that activity of the enzyme galactosyltransferase peaks before that of sialyltransferase during the oestrous cycle (Nelson et al., 1977). It is therefore possible that progesterone treatment results in glycoprotein synthesis, but that 
the early products contain more unfinished chains (i.e. more free galactose residues) than the later products, resulting in an early peak in immunosuppression with phytohaemagglutinin.

Taken together, the data strongly indicate that it is not the actual concentration of progesterone which is physiologically important, but rather changes in progesterone values. It seems likely that the increasing levels of progesterone observed in normal cyclic animals as well as pregnant animals from Days 0 to 16 are also accompanied by changes in serum immunosuppression, sialic acid and sialyltransferase activity. This work provides a preliminary basis for studying the potential role of glycoproteins in immunosuppression by steroids and during pregnancy.

This work was supported by the Maine Agriculture Experiment Station (Hatch Project 8407).

\section{References}

Bazer, F.W. \& First, N.L. (1983) Pregnancy and parturition. J. Anim. Sci. 57, 425-460.

Beer, A.E., Billingham, R.E. \& Scott, J.R. (1975) Immunogenetic aspects of implantation, placentation and feto-placental growth rates. Biol. Reprod. 12 , 176-189.

Butcher, R.L., Collins, W.E. \& Fugo, N.W. (1974) Plasma concentrations of $\mathrm{LH}, \mathrm{FSH}$, prolactin, progesterone and estradiol-17 $\beta$ throughout the 4-day estrous cycle of the rat. Endocrinology 94, 1704-1708.

Clemens, L.E., Siiteri, P.K. \& Stites, D.P. (1979) Mechanism of immunosuppression of progesterone on maternal lymphocyte activation during pregnancy. $J$. Immun. 122, 1978-1985.

Dairaku, K., Miyagi, T., Wakui, A. \& Tsuiki, S. (1983) Increase in serum sialyltransferase in tumor-bearing rats: the origin and nature of the increased enzyme. Gann 74, 656-662.

Etzel, B.J., Murray, F.A., Grifo, A.P., Jr \& Kinder, J.E. (1978) Partial purification of uterine secretory protein capable of suppressing lymphocyte reactivity in vitro. Theriogenology 10, 469-480.

Hellstrom, K.E., Hellstrom, I. \& Brawn, J. (1969) Abrogation of cellular immunity to antigenically foreign mouse embryonic cells by a serum factor. Nature, Lond. 224, 914-915.

Hsu, C.C.S. (1974) Peripheral blood lymphocyte responses to phytohemagglutinin and pokeweed mitogen during pregnancy. Proc. Soc. exp. Biol. Med. 146, $771-775$.

Hulka, J.F., Mohr, K. \& Lieberman, M.W. (1965) Effect of synthetic progestational agents on allograft rejection and circulating antibody production. Endocrino$\log y$ 77, 897-901.

Kaplan, H.A., Woloski, B.M.R.N.J., Hellman, M. \& Jamieson, J.C. (1983) Studies on the effect of inflammation on rat liver and serum sialyltransferase. J. biol. Chem. 258, 11505-11509.

Kasakura, S. (1971) A factor in maternal plasma during pregnancy that suppresses the reactivity of mixed leucocyte cultures. J. Immun. 107, 1296-1301.

Koch, E., Morton, H. \& Ellendorff, F. (1983) Early pregnancy factor: biology and practical application. Br. vet. J. 139, 52-58.

Leikin, S. (1972) Depressed maternal lymphocyte response to phytohaemagglutinin in pregnancy. Lancet 2,43 .
Lowry, O.H., Rosebrough, N.J., Farr, A.L. \& Randall, R.J. (1951) Protein measurement with the folin phenol reagent. J. biol. Chem. 193, 263-275.

Manak, R.C. (1981) Pregnancy-associated immunoregulation of bovine lymphocytes. $A d v$. exp. Med. Biol. 137, 767.

Mori, T., Kobayashi, H., Nishimura, T., Mori, T.S., Fujit, G. \& Inou, T. (1975) Inhibitory effect of progesterone on the phytohaemagglutinin-induced transformation of human peripheral lymphocytes. Immun. Commun. 4, 519-527.

Murray, F.A. \& Chenault, J.R. (1982) Effects of steroids on bovine T-lymphocyte blastogenesis in vitro. $J$. Anim. Sci. 55, 1132-1138.

Nelson, J.D., Jato-Rodriguez, J.J. \& Mookerjea, S. (1975) Effect of ovarian hormones on glycosyltransferase activities in the endometrium of ovariectomized rats. Archs Biochem. Biophys. 169, 181-191.

Nelson, J.D., Jato-Rodriguez, J.J., Labrie, F. \& Mookerjea, S. (1977) Glycosyltransferase and UDP-galactose pyrophosphatase activities in the endometrium during the oestrous cycle of the rat. J. Endocr. 73, 53-58.

Purtilo, D.T., Hallgren, H.M. \& Yunis, E.J. (1972) Depressed maternal lymphocyte response to phytohaemagglutinin in human pregnancy. Lancet 1, 169171 .

Roberts, G.P. (1977) Inhibition of lymphocyte stimulation by bovine uterine proteins. J. Reprod. Fert. S0, $337-339$.

Sarcione, E.J., Delluomo, D. \& Zloty, M. (1983) Pregnancy-associated alpha 2 glycoprotein $\left(\alpha_{2}\right.$ PAG) synthesis by human breast cancer tissue and cultured cell lines. Int. J. Cancer 31, 143-147.

Sheffel, W.E., Pratt, B.R., Ferrell, W.L. \& Inskeep, E.K. (1982) Induced corpora lutea in the postpartum beef cow. II. Effects of treatment with progestogen and gonadotropins. J. Anim. Sci. 54, 830-836.

Sherblom, A.P. \& Bourassa, C.R. (1983) Specificity of submaxillary gland sialyltransferases. Biochim. Biophys. Acta 761, 94-102.

Silver, H.K.B., Karim, K.A., Archibald, E.L. \& Salinas, F.A. (1979) Serum sialic acid and sialyltransferase as monitors of tumor burden in malignant melanoma patients. Cancer Res. 39, 5036-5042.

Silver, H.K.B., Murray, N., Worth, A.J., Salinas, F.A. \& Spinelli, J.J. (1983) Prediction of malignant melanoma recurrence by serum $\mathrm{N}$-acetylneuraminic acid. Int. J. Cancer 31, 39-43. 
Singh, B.N. \& Lucas, J.J. (1981) Increased transfer of oligosaccharide from oligosaccharide pyrophosphoryl dolichol to protein acceptors upon estrogeninduced chick oviduct differentiation. J. biol. Chem. 256, 12018-12022.

Staples, L.D., Fleet, I.R. \& Heap, R.B. (1982) Anatomy of utero-ovarian lymphatic network and the composition of afferent lymph in relation to the establishment of pregnancy in the sheep and goat. J. Reprod. Fert. 64, 409-420.

Stites, D.P. \& Sitteri, P.K. (1983) Steroids as immunosuppressants in pregnancy. Immunol. Rev. 75, 117138.

Stites, D.P., Bugbee, S. \& Siiteri, P.K. (1983) Differential actions of progesterone and cortisol on lymphocyte and monocyte interaction during lymphocyte activation-relevance to immunosuppression in pregnancy. J. Reprod. Immunol. 5, 215-228.

Van Dijk, W., Lasthuis, A. M., Trippelvite, L.A.W. \& Muilerman, H.G. (1983) Increased glycosylation in regenerating rat liver is paralleled by decreased activities of CMP-N-acetylneuraminate hydrolase and UDP-galactose pyrophosphatase. Biochem. J. 214, 1003-1006.

Warren, L. (1959) The thiobarbituric acid assay of sialic acids. J. biol. Chem. 234, 1971-1975.

Watnick, A.S. \& Russo, R.A. (1968) Survival of skin homografts in uteri of pregnant and progesteroneestrogen treated rats. Proc. Soc. exp. Biol. Med. 128, $1-4$.

Received 25 September 1984 